\title{
ANÁLISE DO GRAU DE INTEGRAÇÃO ENTRE OS PAÍSES DO MERCOSUL A PARTIR DA HIPÓTESE DA PARIDADE DA TAXA DE JUROS REAL
}

\author{
ANALYSIS OF THE DEGREE OF INTEGRATION BETWEEN THE MERCOSUL \\ COUNTRIES USING THE REAL INTEREST RATE PARITY HYPOTHESIS
}

\author{
Livia Semensato Sacchetti $i^{(*)}$ \\ Banco Itaú Unibanco S.A., São Paulo (SP), Brasil \\ Alex Luiz Ferreira ${ }^{(* *)}$ \\ Universidade de São Paulo, São Paulo (SP), Brasil
}

Resumo: Verificou-se formalmente o grau de integração conjunta dos mercados de bens e ativos entre os países do Mercosul: Argentina, Brasil, Paraguai e Uruguai. A investigação foi realizada para o período entre julho de 1995 a setembro de 2011, por meio da análise das séries de tempo dos diferenciais de taxa de juros reais entre os mesmos. O conjunto dos resultados dos testes bilaterais aponta na direção de estacionariedade dos diferenciais dos países-membros, sendo esses corroborados pelos dados em painel. As medidas de persistência estimadas evidenciam que o processo de integração combinada aumentou ao longo do período amostral, ainda que lentamente.

Palavras-chave: Hipótese da Paridade da Taxa de Juros Real; Integração Financeira; Mercosul.

Abstract: The aim of this paper is to assess the degree of financial and trade integration among the members of Mercosul (Argentina, Brazil, Paraguay and Uruguay) from July/1995 to September/2011, through the time-series analysis of real interest rate differentials. Unit root tests were performed to both panel and bilateral series, considering the presence of structural breaks. The differentials are then approximated by an AR(1) and its coefficients, estimated recursively and by rolling window, are analyzed. Persistence measures pointed to an increasing, albeit slow, market integration during the period analyzed.

Keywords: Real Interest Parity Hypothesis; financial integration; Mercosul.

(*) Mestre, Analista do Banco Itaú Unibanco S.A. E-mail: < livia.s.sacchetti@gmail.com>.

$(* *)$ Doutor, Professor da Faculdade e Economia, Administração e Contabilidade da Universidade de São Paulo, Campus Ribeirão Preto. E-mail:<alexferreira@usp.br>. Recebido em 21.03.2014, aceito em: 10.10.2014. 


\section{INTRODUÇÃO}

Em 1991, Brasil, Argentina, Paraguai e Uruguai assinaram o Tratado de Assunção, que previa a constituição do Mercado Comum do Sul (Mercosul) em dezembro de 1994. Apesar do objetivo de jure de maior integração entre os Estados-partes, esse artigo investiga do ponto de vista econômico se há, de facto, maior integração. Para esse propósito, investiga-se o grau de integração financeira e comercial entre Brasil, Argentina, Paraguai e Uruguai (os primeiros países do bloco), para o período de julho de 1995 a setembro de 2011, por meio da análise das séries de tempo dos diferenciais de taxa de juros reais (rids) desses países.

A utilização dos rids como medida de integração financeira fundamenta-se na hipótese da paridade da taxa de juros real (HPTJ), que prediz que se os agentes formam suas previsões sob o pressuposto das expectativas racionais, se não há fricções nos mercados de bens e ativos (tais como cotas de importações, custos de transação, assimetrias informacionais, etc.), os preços relativos dos bens homogêneos avaliados na mesma moeda e as taxas reais de retorno esperadas dos ativos deverão ser iguais. No caso de uma integração dos mercados de bens e ativos entre os países, o diferencial da taxa de juros real entre eles deveria ser nulo na média ou, pelo menos, deveria ser apenas de curto prazo.

O estudo do grau de integração financeira e comercial entre os países também propicia um melhor entendimento acerca da propagação das crises econômicas, isto é, de como um choque adverso originado em uma economia pode afetar as demais.

Desde a década de 1990, o mundo passou por diversas crises econômico-financeiras: mexicana (1994-1995), asiática (1997-1998), russa (1998), argentina (2001) e a norte-americana (2008-2010), além da europeia, talvez ainda em curso. Cada uma delas produziu resultados diferentes nos países afetados, que dependem de características próprias de cada país, bem como do grau de integração com o epicentro da crise. Quando há uma alta integração financeira entre os países, os choques são transmitidos de forma mais intensa e rápida. Com isso, a análise do grau de integração entre os países é capaz de fornecer informações úteis sobre a consequência de um choque em uma economia sobre as demais.

Como notado por Ferreira (2005), além da utilização dos rids como medida do grau de integração, eles ainda podem servir como sinalizadores da independência da política monetária e como indicadores de solvência do país. Em primeiro lugar, a análise dos rids possibilita à autoridade monetária uma melhor compreensão de como deverá conduzir sua política econômica em uma economia aberta e pequena, pois, se a HPTJ for válida, a eficácia da política monetária doméstica estaria restrita e sujeita a influências da taxa de juros real mundial, como sugerem os modelos-padrão de macroeconomia aberta. Além disso, rids elevados (positivos) e persistentes poderiam indicar problemas de solvência numa economia endividada. Isto porque o país deverá desviar parte de seu produto para o pagamento do serviço da dívida, o que, por sua vez, reduziria o montante disponível para investimento, dimunuindo a taxa de crescimento da economia. Caso a taxa de juros real seja mais elevada que a taxa de crescimento da renda, o país não conseguirá honrar seus pagamentos incorrendo em default, assintoticamente. 
Os países selecionados para este estudo somam 2,9\% do PIB mundial ${ }^{(1)}$. Apesar da relativamente baixa participação destes países no produto global, destaca-se um grande avanço no comércio intra e extrabloco depois da formação do Mercosul, bem como uma relativa estabilidade macroeconômica durante a maior parte do período amostral estudado, favorecendo os fluxos comerciais e financeiros entre os países. Mais adiante, serão revelados indícios descritivos de que houve aumento da integração comercial e financeira durante o período estudado, o que torna a aplicação da teoria da HPTJ particularmente interessante.

Outra evidência apontada para os países em estudo foi levantada por Seabra (2002) que avaliou o grau de integração dos países-membros do Mercosul e o mercado internacional, representado pelos Estados Unidos. O autor aplicou testes de raiz unitária nas séries de diferenciais de taxas de juros reais entre cada país-membro e os Estados Unidos e depois nos dados agrupados em painel, considerando o período de março de 1991 a abril de 2000 (frequência mensal). A conclusão dos testes univariados é que a série do Paraguai é estacionária enquanto que a da Argentina, Brasil e Uruguai não o são, porém, as séries são cointegradas ${ }^{(2)}$, revelando evidências de convergência dos países para a taxa de juros real internacional. Já o resultado apresentado pelos testes de painel apontam para a não integração dos países-membros com o mercado internacional.

O presente estudo, como em Seabra (2002), realiza testes de raiz unitária individualmente nas séries bilaterais dos países do Mercosul e também nos dados em painel. Além da possibilidade de utilizar uma amostra mais longa de dados e que, portanto, pode refletir com mais precisão a história recente do Mercosul, esse trabalho complementa Seabra (2002) em vários aspectos importantes. Em primeiro lugar porque, diferentemente deste autor, analisa-se diretamente o grau de integração entre os próprios países do Mercosul e não entre os países-membros com os Estados Unidos da América (EUA). A razão é que um país A e um país B podem estar individualmente integrados com outro país $C$, mas isso não necessariamente implica que A e B também estão comercial e financeiramente integrados. Além disso, serão desenvolvidos testes mais robustos para a análise dos diferenciais de juros entre países, investigando-se a presença de possíveis mudanças estruturais. Já, para a análise dos dados em painel, serão implementados testes acerca da independência das variáveis dentro do painel. Essa observação é crucial, pois no artigo de Seabra (2002) as variáveis estão correlacionadas por definição, isto é, o diferencial de juros Brasil e EUA têm vinculações com o diferencial de juros Argentina e EUA e assim por diante. Finalmente, usando-se ideias dos trabalhos de Ferreira e León-Ledesma (2007) e de Dias e Marques (2005) aproximou-se os rids por um processo autorregressivo de ordem um, AR(1), e avaliou-se o comportamento dos coeficientes estimados tanto recursivamente quanto via janela móvel. A partir dessa análise, também se construíram algumas medidas de velocidade de ajustamento para verificar o quão persistentes são os rids, quantificando o tempo para que um dado choque se dissipe.

(1) Participação do Produto Interno Bruto no total mundial baseado na Paridade do Poder de Compra (PPC), 2009 , FMI.

(2) Seguindo o procedimento de Johansen (1988), Seabra (2002) encontra evidências para a não rejeição da hipótese nula de não estacionariedade, tanto pelo critério de máximo do autovalor como pela estatística do traço. 
Os resultados encontrados apontam, de forma geral, para a estacionariedade dos diferenciais. O teste ADF rejeitou a raiz unitária para todas as séries, enquanto o DF-GLS rejeitou para três dos seis diferenciais. Quando se considera a presença de quebras estruturais (teste de Zivot \& Andrews, 1992), os resultados mostram que todas as séries são estacionárias. Enfim, os resultados apresentados não são unânimes, mas existe um conjunto razoável de evidências que apontam para uma maior integração (comercial e financeira) entre os países do Mercosul durante o período amostral. Com relação à estimação dos coeficientes autorregressivos e das medidas de persistência, também se verificou um aumento da integração entre os países, ainda que de forma lenta.

O presente artigo é composto por esta introdução e por mais quatro seções. $\mathrm{Na}$ primeira seção, será exposta uma revisão teórica da HPTJ. Na segunda seção, será realizada um breve resumo sobre a evolução da integração financeira e comercial entre os países-membros do bloco. Na terceira seção, serão apresentadas as metodologias a serem utilizadas e os resultados. Por fim, serão apresentadas as considerações finais.

\section{TEORIA}

A abertura multilateral dos mercados (financeiro e comercial) dos países propicia um maior fluxo de transações de bens e ativos externos nas economias envolvidas. Portanto, quanto maior a integração, menor será a diferença entre os preços de bens e ativos dessas economias, quando expressos na mesma moeda.

Como anteriormente colocado, uma forma de se testar a integração financeira e comercial de facto entre os países é mediante a análise dos rids. Esta análise tem como base teórica a HPTJ, que agrupa os conceitos de equilíbrio dos mercados de bens e de ativos.

O equilíbrio no mercado de bens pode ser expresso pela hipótese da Paridade do Poder de Compra (PPC absoluta) que implica que os níveis de preços entre dois países devem ser iguais quando convertidos à mesma moeda (Lei do Preço Único). Esta hipótese é baseada em um mercado sem fricções e de bens homogêneos, em que não há oportunidades de arbitragem. A abordagem relativa da PPC considera que as variações da taxa de câmbio estão proporcionalmente relacionadas ao diferencial de inflação entre países. Formalmente, a hipótese da PPC relativa pode ser expressa por:

$$
\Delta S_{t}=\pi_{t}-\pi_{t}^{*}
$$

Onde $S_{t}$ é a taxa nominal de câmbio definida em termos de moeda doméstica relativamente à moeda estrangeira; a taxa de depreciação esperada para a moeda local é dada por $\Delta S_{t} \equiv \frac{S_{t}}{S_{t-1}}-1$ para o período "t"; $\pi_{t} \equiv \frac{P_{t}}{P_{t-1}}-1$ é a taxa de inflação doméstica para o período t; e, quando sobrescrita com “*”, tem-se sua representação para os países estrangeiros.

Já, para o mercado de ativos, tem-se a Hipótese da Paridade da Taxa de Juros Descoberta (PTJD) que implica em equivalência dos retornos esperados dos ativos dos países (para o mesmo nível de risco), desde que exista um mercado com alta mobilidade de capital em que, novamente, não persistam oportunidades de especulação, isto é, os 
agentes exploram as oportunidades de se obter um lucro esperado com a compra e venda de ativos domésticos e estrangeiros. Sob o pressuposto de que os agentes formam expectativas racionais e também são neutros ao risco, a relação de equilíbrio no mercado de ativos pode ser expressa da seguinte forma:

$$
\begin{aligned}
& i_{t} \cong i_{t}^{*}+\Delta S_{t}^{e} \\
& \Delta S_{t}^{e}=\Delta S_{t}+\varepsilon_{t}
\end{aligned}
$$

Em que $i_{t}$ é a taxa de juros nominal doméstica; $i_{t}^{*}$ é a taxa de juros nominal internacional; $\Delta \mathrm{S}_{\mathrm{t}}^{\mathrm{e}}=\frac{\mathrm{S}_{\mathrm{t}+1}^{\mathrm{e}}}{\mathrm{S}_{\mathrm{t}}}-1$ é a taxa de depreciação esperada para a moeda local em termos de moeda estrangeira; $\mathrm{S}_{\mathrm{t}+1}^{\mathrm{e}}$ é a taxa de câmbio esperada para $\mathrm{t}+1$ condicional ao conjunto de informações em t; e $S_{t}$ é a taxa de câmbio nominal para o período t. A PTJD descrita em (2.2) indica que as taxas de juros dos países tendem a caminhar juntas, a menos que ocorram grandes variações nas taxas de câmbio atual e esperada. Já a equação (2.3) ilustra que a depreciação esperada da moeda difere da depreciação efetiva $\left(\Delta \mathrm{S}_{\mathrm{t}}\right)$ apenas por um ruído independente e identicamente distribuído, $\varepsilon_{t} \sim N\left(0, \sigma_{\varepsilon}^{2}\right)$, por hipótese das expectativas racionais.

Supondo que a PPC relativa e a PTJD sejam válidas, podem-se unir as equações (2.1), (2.2) e (2.3) e chegar-se à seguinte relação que define os rids:

$$
\begin{aligned}
& \operatorname{rid}_{t}=\left(i_{t}-\pi_{t}\right)-\left(i_{t}^{*}-\pi_{t}^{*}\right) \\
& \operatorname{rid}_{t}=\varepsilon_{t}
\end{aligned}
$$

Portanto, se a PPC e a PTJD são válidas, isto é, se há arbitragem, especulação e ausência de fricções nos mercados, os diferenciais de juros reais devem se comportar como um ruído independente e identicamente distribuído, $E\left(\right.$ rid $\left._{t}\right)=0$. Se esta propriedade for atendida, concluir-se-á que há integração plena dos países em questão.

Entretanto, violações nas hipóteses da PPC relativa e da PTJD sob expectativas racionais podem gerar resultados diferentes do predito por (2.4). Assim, para realizar a análise do comportamento dos rids, é necessário compreender seus determinantes e os fatores que influenciam sua possível persistência temporal, isto é, cabe verificar alguns dos possíveis fatores que ocasionam a falha da PPC relativa e/ou da PTJD e/ou das expectativas racionais e que devem ser consideradas na análise dos rids.

Ferreira e Silva (2009) salientam esse ponto ao dividir a volatilidade dos rids entre desvios causados pelos desvios da PPC e por desvios da PTJD. Os autores analisam dados de 1995 a 2004 de alguns países emergentes (Argentina, Brasil, Chile, México e Turquia), concluindo que, para os países estudados, os desvios da HPTJ foram causados majoritariamente por desvios na PTJD. Conforme apontado por Ferreira (2005), tais desvios (da PTJD) estão relacionados ao enigma colocado por Feldstein \& Horioka (1980), os quais apontaram uma alta correlação entre a taxa de poupança doméstica e investimento doméstico para os países da OCDE de 1960 até meados de 1970. Esta evidência contraria a PTJD pois, em um ambiente de perfeita mobilidade de capital e livre arbitragem, o ca- 
pital deveria fluir para os países que apresentassem maiores taxas de retornos esperadas líquidas de impostos de forma que a correlação entre a taxa de poupança doméstica e a de investimento fossem baixas.

Desvios da PTJD podem estar correlacionados com uma taxa de risco, cambial ou de default, que não é invariante ao tempo ou com custos de transação (esses com maior probabilidade de serem relativamente estáticos). Nesse sentido, cabe ressaltar o artigo de Ferreira \& León-Ledesma (2007). Os autores analisaram um conjunto de países desenvolvidos e de emergentes para o período de 1995 até 2002 e concluíram pela validade da HPTJ. Os autores mostraram que, enquanto os países desenvolvidos convergem para um diferencial de taxa de juros próximo ou igual a zero, os países emergentes convergem para um diferencial positivo, possivelmente correlacionado com o prêmio de risco.

Entretanto, ressalta-se ainda que o surgimento dos desvios da PTJD também podem ser explicados por problemas de especificação do modelo utilizado. Este fator é levantado por Ferreira (2008) que, baseado numa ideia de McCallum (1995), desenvolveu um modelo em que as falhas da PTJD devem-se a uma relação de simultaneidade entre a função de reação da Autoridade Monetária com a função da PTJD. Isto ocorre pois a função de reação da autoridade monetária é caracterizada por um ajuste lento da taxa de juros e resistência a alterações na taxa de câmbio. A partir de dados ex ante para o Brasil e sob os pressupostos de expectativas racionais e mercado incompleto de informação, o autor demonstra que os desvios da PTJD podem surgir por causa da ação simultânea do Banco Central e dos especuladores e, quando considerado este problema, esta hipótese passa a ser verificada.

Não se pretende fazer uma revisão exaustiva sobre os trabalhos que estudam os desvios da PTJD, o que está fora do escopo do presente trabalho, mas é preciso finalmente ressaltar que a mesma pode se assentar na quebra do seu terceiro pilar, o pressuposto de expectativas racionais. Chakraborty \& Evans (2008) demonstram que desvios da expectativa racional, ainda que pequenos podem gerar um grande viés no parâmetro estimado para a relação da PTJD. As fricções apresentadas até aqui são algumas das possíveis causas para o surgimento dos rids no curto prazo. Há, contudo, evidências empíricas de que a HPTJ se verifica no longo prazo, podendo ocorrer lentamente (Meredith e Chinn, 1998) e o mesmo aconteceu com a PPC (ver Rogoff, 1996).

Assim, deve-se analisar tanto a dinâmica de curto quanto de longo prazo para a análise da integração entre os países. Para isso, supõe-se como em Ferreira \& León-Ledesma (2007) que os rids podem ser representados no curto prazo por um processo autorregressivo, por hipótese simplificadora um $\operatorname{AR}(1)$, tal que:

$$
\operatorname{rid}_{t}=a_{0}+a_{1} \text { rid }_{t-1}+\varepsilon_{t}
$$

Supondo uma condição inicial conhecida e a estacionariedade de rids, ou seja, $\left|a_{1}\right|<1$, o processo (2.5) pode ser escrito como:

$$
\operatorname{rid}_{t-1}=a_{0} \sum_{i=0}^{t-1} a_{1}^{i}+a_{1}^{t} r i d_{0}+\sum_{i=0}^{t-1} a_{1}^{i} \varepsilon_{t-1}
$$

Para sua representação de longo prazo, calcula-se o limite para quando t tende ao infinito para a equação (2.6) e aplica-se o operador de esperança: 


$$
\lim _{t \rightarrow \infty} E\left(\text { rid }_{t}\right)=\frac{a_{0}}{1-a_{1}}
$$

Portanto, para que $\mathrm{E}\left(\right.$ rid $\left._{\mathrm{t}}\right)=0$, é preciso que $\mathrm{a}_{0}$, intercepto de (2.5), também seja igual a zero. Relembrando que, sob a hipótese de estacionariedade, é necessário que $a_{1}$ seja diferente de 1 , ou a esperança não estará bem definida. Assim, será realizado um teste de raiz unitária nos diferenciais de juros descritos em (2.5), com um modelo mais geral do lado direito de (2.5), de forma a garantir resíduos bem comportados e permitir a inferência estatística, que resulta em:

$$
\Delta \operatorname{rid}_{t}=a_{0}+\rho \operatorname{rid}_{t-1}+\sum_{i=2}^{p} \beta_{i} \Delta r i d_{t-i+1}+\varepsilon_{t}
$$

em que

$$
\rho=\sum_{1=2}^{p} a_{i}-1
$$

O teste de integração dos mercados consiste, portanto, em investigar: (i) se $\rho=0$ (há raiz unitária) contra $\rho<0$ (rids é estacionário); e (ii) se $\mathrm{a}_{0}=0$ (diferencial de juros é zero) contra $\mathrm{a}_{0}>0$ (diferencial de juros é positivo). Portanto, se a raiz unitária é rejeitada, pode-se investigar a dinâmica das séries por medidas de persistência, como será mostrado na seção 4. Antes, porém, serão apresentadas evidências narrativas de que o processo de consolidação da estabilidade econômica da década de 1990 e 2000 e a criação do Mercosul propiciaram uma maior integração dos mercados de bens e ativos entre os países-membros.

\section{EVOLUÇÃO DA INTEGRAÇÃO NO MERCOSUL}

Em 1991, Brasil, Argentina, Paraguai e Uruguai assinaram o Tratado de Assunção, que previa a constituição do Mercado Comum do Sul (Mercosul). Este processo de transição para a integração econômica deveria ocorrer de forma gradual até o final do ano de 1994. O objetivo principal da formação do mercado comum é explicitado no Artigo I desse tratado, o qual estabelece: I. "A livre circulação de bens, serviços e fatores produtivos entre os países, através, entre outros, da eliminação dos direitos alfandegários e restrições não tarifárias à circulação de mercadorias e de qualquer outra medida de efeito equivalente"; II. "O estabelecimento de uma tarifa externa comum (TEC) e a adoção de uma política comercial comum em relação a terceiros Estados ou agrupamentos de Estados e a coordenação de posições em foros econômico-comerciais regionais e internacionais"; III. "A coordenação de políticas macroeconômicas e setoriais entre os Estados-partes de comércio exterior, agrícola, industrial, fiscal, monetária, cambial e de capitais, de outras que se acordem, a fim de assegurar condições adequadas de concorrência entre os Estados-Partes"; e IV. "Compromisso dos Estados Partes de harmonizar suas legislações, nas áreas pertinentes, para lograr o fortalecimento do processo de integração."

Buscando avaliar se os principais objetivos do tratado foram alcançados, Pamplona e Fonseca (2009) identificaram quatro períodos na história do Mercosul: I. de 1991 a 
1994; II. de 1995 a 1998; III. de 1999 a 2002; e IV. de 2003 em diante. O primeiro período foi marcado por um cenário externo favorável e um aumento do comércio entre os países, impulsionado principalmente pelo Programa de Liberalização Automática, que previa o corte linear nas tarifas aduaneiras dos quatros países. Ao final desse período, grande parte dos produtos já estavam sendo comercializados com tarifas zero. As exportações intrabloco obtiveram um crescimento médio no período de $30 \%$, enquanto que no extrabloco esse número foi de 5\%, o que pode ser visualizado no Gráfico 01 (Anexo).

Azevedo e Massuquetti (2009) ressaltam ainda que este período foi favorecido pelo movimento de redução das tarifas médias de importação iniciado na década de 1980 nos países da América Latina, inclusive nos países-membros do Mercosul. Conforme pode ser verificado pelo Gráfico 02 (Anexo), todos os países-membros do Mercosul apresentaram redução na tarifa média de importação de 1985 para 1991, em especial o Brasil que mostrou o maior decaimento.

O segundo período foi marcado pela implantação da Tarifa Externa Comum (TEC), com o objetivo de aumentar a competitividade entre os países-membros do Mercosul para reduzir a probabilidade de formação de oligopólios ou de reservas de mercado. A princípio, as tarifas de importação extrabloco deveriam convergir para uma tarifa comum, a TEC, até 1995, mas, desde o início, permitiu-se que alguns produtos poderiam convergir em períodos posteriores. Por exemplo, para produtos de bens de capital e equipamentos de tecnologia da informação, Argentina e Brasil convergiriam para a TEC de 14\% até 2001, enquanto o Paraguai e o Uruguai deveriam convergir até o ano de 2006 (Azevedo e Massuquetti, 2009). Apesar da existência dessas exceções, conforme pode ser verificado no Gráfico 02, o ano de 1995 é o que apresenta um dos menores patamares de tarifa média. Outro ponto a ser levantado acerca do segundo período é que este foi marcado por um crescimento nas relações comerciais apresentando crescimento de $15 \%$ no intrabloco e 5\% no extrabloco. Pamplona e Fonceca (2009), afirmam que esse período foi beneficiado pelas políticas macroeconômicas convergentes dos dos maiores sócios do bloco (Argentina e Brasil) gerando benefícios para todos os demais membros. Porém, em 1998, em razão do cenário externo desfavorável (crise russa e asiática), houve uma redução no avanço do processo de integração do bloco.

O cenário adverso se estendeu para o terceiro período, sendo este marcado por mais crises econômicas (1999, crise da desvalorização da moeda brasileira e 2001, crise argentina) e uma redução ainda maior do processo de integração. Conforme apontado por Pamplona e Fonseca (2008) e Bauman (2001), os países preferiram a diversificação de seus parceiros comerciais diante do cenário macroeconômico internacional desfavorável. Esse movimento se refletiu em um maior grau de abertura comercial ${ }^{(3)}$ do bloco a partir de então, mostrado no Gráfico 03 (Anexo).

Por fim, no quarto período, houve uma melhora do cenário macroeconômico e o processo de integração passou a ser retomado. As exportações intrabloco cresceram em média 22\% no período 2003 a 2011, enquanto que as do extrabloco, 17\%. Pamplona e

(3) O grau de abertura do Mercosul calculado por $G A=(1 / 2)(X+M / P I B)$, onde $X$ e $M$ são as exportações e importações do Mercosul (Von Doellinger \& outros, 1974). 
Fonseca (2009) também ressaltam a importância da convergência das políticas cambiais, retomada do crescimento econômico da região e a posse de presidentes favoráveis ao bloco. Um outro ponto de destaque desta fase foi a criação do Fundo para a Convergência Estrutural e Fortalecimento do Mercosul (Focem) em junho de 2005, a fim de financiar obras de infraestruturas das economias menores, reduzindo as possíveis desigualdades. Este é um fundo destinado ao financiamento de projetos, sendo estes divididos em quatro programas de acordo com o seu respectivo objetivo. São eles: I. Programa de Convergência Estrutural, relacionado a projetos de infraestrutura (transporte, energia, hídrico); II. Programa de desenvolvimento da competitividade, que atende projetos que contribuem para o aumento de competitividade das atividades produtivas dos países-membros; III. Programa de Coesão Social, que apoia projetos de desenvolvimento social (educação, pobreza, desemprego, etc.); e IV. Programa de fortalecimento da estrutura institucional e do processo de integração, cujos projetos estão relacionados ao aprimoramento da integração entre os países do bloco ${ }^{(4)}$.

Apesar dos inúmeros órgãos e decisões implantados e que buscam o aprofundamento da integração financeira entre os países do Mercosul, Moreira e Milhomem (2010) ressaltam algumas ineficiências ainda presentes, tais como nível reduzido da integração energética, da infraestrutura e da livre circulação de mão de obra; políticas de fronteiras pouco definidas, etc.

Além da análise do fluxo de bens entre os países, também devem-se verificar as ligações financeiras entre eles. Para a melhor compreensão dessa variável, cabe uma breve análise da estrutura do sistema financeiro desses países, pois este é o fator de maior relevância para a determinação do fluxo de capitais.

Durante a década de 90, os principais países-membros do Mercosul implementaram mudanças importantes, tais como a da redução do papel do Estado na intermediação financeira, maior abertura comercial além de políticas de estabilização macroeconômica, tornando-os mais atrativos ao investimento e ao comércio exterior. No entanto, as barreiras financeiras ainda parecem ser significativas impedindo o maior desenvolvimento desses mercados. Segundo Mendonça (2009), dentre os países do bloco, o Brasil é o que apresenta o maior e mais complexo sistema financeiro, com um mercado de capitais bem desenvolvido e integrado com os mercados internacionais, além de uma estrutura bem consolidada do mercado de crédito de longo prazo. Já os demais países apresentam instrumentos de financiamento mais voltados para o curto prazo e, com exceção da Argentina, o mercado de capitais é inexpressivo.

Além de uma estrutura ineficiente do mercado de capitais, deve-se ressaltar ainda que as políticas econômicas dos países do Mercosul não são deliberadamente coordenadas, apesar de haver um objetivo explícito da harmonização de alguns indicadores.

(4) Observa-se, no entanto, que o aporte anual estipulado para o Focem é muito baixo em relação ao tamanho das economias: de US\$ 100 milhões para o período de 2006 a 2015, dividindo-se as contribuições da seguinte forma: Argentina, 27\%; Brasil, 70\%; Uruguai, 2\%; e Paraguai, 1\%. A utilização desses recursos foi previamente determinada seguindo: 48\% destinados a projetos apresentados pelo Paraguai; $32 \%$, para os projetos apresentados pelo Uruguai; $10 \%$, para os projetos apresentados pela Argentina; e 10\%, para os projetos apresentados pelo Brasil. 
No ano 2000, foi assinado o acordo de Convergência Macroeconômica tendo como principais metas (Pamplona e Fonseca, 2009): I. a partir de 2002, a variação da dívida fiscal líquida do setor público seria de no máximo 3\% do PIB; II. a partir de 2010, a dívida líquida do setor público ficaria limitada a 40\% do PIB; III. a partir de 2006, o "núcleo inflacionário" não deveria ser superior a 3\% ao ano; além da criação de um grupo de monitoramento macroeconômico e a harmonização de algumas medidas e práticas vigentes.

Avaliando tais metas durante o período amostral relevante, nota-se que tanto Brasil quanto Uruguai apresentaram convergência da razão dívida/PIB, ficando próximos da meta em 2010. Mas, de forma geral, os indicadores de inflação desses países ficaram longe dos objetivos. Observa-se, portanto, que, apesar dos acordos formais assinados, o processo de convergência macroeconômica e de integração depende da circunstância econômica e política de cada país-membro. Uma análise quantitativa torna-se, por conseguinte, interessante, pois avalia se os dados refletem a vontade política de maior integração entre os países do bloco.

\section{METODOLOGIA E RESULTADOS}

A realização do teste de raiz unitária entre dois países do Mercosul tem por finalidade a verificação do grau de integração financeira e comercial entre eles. Para isso, a construção do diferencial da taxa de juros real entre dois países é dada por:

$$
\operatorname{rid}_{m n, t}=\left(i_{t}-\pi_{t}\right)-\left(i_{t}^{*}-\pi_{t}^{*}\right)
$$

Em que os índices $n$ e $m$ representam dois países quaisquer do conjunto de países-membros do Mercosul; $i_{t}$ representa a taxa de juros nominal no instante $t$; $\pi_{\mathrm{t}}$ é a taxa nominal de inflação ao produtor para o instante $t$.

\begin{tabular}{|c|c|}
\hline VARIÁVEL & DIFERENCIAL DA TAXA DE JUROS ENTRE \\
\hline$r i d_{a b, t}$ & Argentina e Brasil \\
\hline$r i d_{a p, t}$ & Argentina e Paraguai \\
\hline$r i d_{a u, t}$ & Argentina e Uruguai \\
\hline$r i d_{b p, t}$ & Brasil e Paraguai \\
\hline$r i d_{b u, t}$ & Brasil e Uruguai \\
\hline$r i d_{p u, t}$ & Paraguai e Uruguai \\
\hline
\end{tabular}

\section{QUADRO 01 \\ RIDS USADOS NA ANÁLISE}

A verificação do grau de integração entre dois países $n$ e $m$ será realizada por meio do teste de raiz unitária sobre o rid ${ }_{\mathrm{nm}, \mathrm{t}}$, conforme explicitado na Quadro 01. Se for constatado que a série dos rid ${ }_{\mathrm{nm}, \mathrm{t}}$ é estacionária, deduz-se que os países $n$ e $m$ possuem algum grau de integração financeira e comercial; caso contrário, a PTJD não será verificada e não haverá indícios de integração. 
Inicia-se a investigação de estacionariedade a partir do teste ADF, que possui como hipótese nula a raiz unitária $(\rho=1)$, isto é, a série apresenta pelo menos uma raiz unitária, tratando-se assim de uma série não estacionária. A aplicação deste teste considera três equações diferentes utilizadas:

$$
\begin{aligned}
& \Delta \operatorname{rid}_{n m, t}=a_{0}+\operatorname{\rho rid}_{n m, t}+\beta_{0} t+\sum_{i=2}^{p} \beta_{i} \Delta \operatorname{rid}_{n m, t-i+1}+\varepsilon_{t} \\
& \Delta \operatorname{rid}_{n m, t}=a_{0}+\operatorname{\rho rid}_{n m, t}+\sum_{i=2}^{p} \beta_{i} \Delta \operatorname{rid}_{n m, t-i+1}+\varepsilon_{t} \\
& \Delta \operatorname{rid}_{n m, t}=\operatorname{\rho rid}_{n m, t}+\beta_{0} t+\sum_{i=2}^{p} \beta_{i} \Delta \operatorname{rid}_{n m, t-i+1}+\varepsilon_{t}
\end{aligned}
$$

A diferença entre estas três regressões deve-se à presença ou não dos termos deterministas de intercepto $\left(a_{0}\right)$ e de tendência linear $\left(\beta_{0} t\right)$. Supondo que rid ${ }_{n m, t}$ é um processo estacionário, tem-se que a equação (4.4) representa um passeio aleatório puro; a equação (4.3), um processo aleatório com intercepto; e a equação (4.2), um processo aleatório com intercepto e tendência linear. A presença dos termos deterministas nas equações, tal que os rids convirjam para uma média de longo prazo diferente de zero, estão possivelmente correlacionados à presença de prêmio de risco específico do país (Ferreira \& León-Ledesma, 2007).

Deve-se ainda considerar alguns cuidados com relação aos resultados deste teste. $\mathrm{O}$ primeiro ponto refere-se ao tamanho da amostra utilizado. Quando em pequenas amostras, o teste ADF apresenta baixo poder, isto é, há uma maior probabilidade de não rejeitar a hipótese nula de presença de raiz unitária quando, em verdade, a série é estacionária. Buscando amenizar esta limitação e visando avaliar a robustez dos resultados encontrados pelo ADF, também será analisado o procedimento DF-GLS, que retira da série de interesse a constante, a tendência e as variáveis explicativas antes de se realizar o teste.

O segundo ponto refere-se à presença de quebras estruturais nas séries. Quando presente, há elevação dos erros do tipo II (não rejeitar a hipótese nula quando a mesma é falsa) nos testes de raiz unitária. Isso se deve ao fato deste elemento poder influenciar o nível e/ou a taxa decrescimento da série.

Para o tratamento dessa questão, a literatura empírica aponta diversas metodologias, destacando-se a inclusão de dummies nos modelos. A escolha do método mais apropriado a ser utilizado é baseado no conhecimento prévio do ponto em que ele ocorre e se ele é único. Para o caso de quebra estrutural em um ponto conhecido, Perron (1989) sugere um teste Dickey-Fuller (DF), considerando três tipos de funções deterministas que incluem dummies para o ponto da quebra. São eles: (i) mudança no coeficiente linear da tendência determinista; (ii) mudança na taxa de crescimento; e (iii) mudança no coeficiente linear da tendência determinista unida a uma alteração na taxa de crescimento.

Entretanto, quando não há o conhecimento prévio do ponto de quebra, a utilização do modelo sugerido por Perron (1989) é inviável. Um modelo utilizado para contornar essa limitação é apresentado por Zivot \& Andrews (1992) em que a hipótese nula é de existência de raiz unitária e a hipótese alternativa estipula que pode ser representado por um processo tendência-estacionário com uma quebra determinística ocorrendo em um ponto desconhecido, porém, possível de ser estimado. 
Para avaliar como a medida de persistência evoluiu ao longo do tempo, optou-se por seguir a seguinte estratégia de modelagem: em primeiro lugar, assumiu-se que os rids podem ser descritos por um processo AR(1). O coeficiente autorregressivo é, então, estimado ao longo da amostra por dois modos: (i) recursivamente, onde o coeficiente em $t=j$ é dado pela regressão que utiliza os dados de a $j$; e (ii) via janela móvel, onde definiu-se um tamanho de janela $H$, e o coeficiente do $\operatorname{AR}(1)$ em $t=j$ é dado pela regressão que utiliza os dados de $j$-H até $j$.

Uma das características da avaliação recursiva em que o período inicial está fixo é a de que os coeficientes convergirão obrigatoriamente para o valor estimado (na regressão simples) para a amostra toda. Isso ocorre porque o peso dado a cada nova observação é decrescente e dado por $1 / t$, em que $\mathrm{t}=1,2, \ldots \mathrm{T}$. Essa diminuição de peso ao londo da amostra pode levar à subestimação de mudanças na persistência, especialmente se estes ocorrem no final da amostra.

O segundo método corrige parcialmente esse problema, ao estimar os coeficientes AR(1) a partir de uma janela móvel fixa. Nesse método, os coeficientes AR(1) levam em conta apenas uma quantidade fixa de dados, permitindo que uma mudança de persistência no final da amostra seja mais rápida em comparação com a estimação recursiva. Em contrapartida, a depender do tamanho da amostra, os valores dos coeficientes podem apresentar elevada volatilidade.

Outra medida de persistência a ser avaliada é a medida de meia-vida definida como o tempo necessário para dissipar o choque pela metade. Ela é expressa por:

$$
\lambda=\frac{\ln \frac{1}{2}}{\ln \left(\alpha_{1}\right)}
$$

Onde $\lambda$ é a meia-vida, e $\alpha_{1}$ é o coeficiente autorregressivo do rid ${ }_{n m, t}$ que segue um processo $\mathrm{AR}(1)$. Quanto maior for o valor estimado para $\alpha_{1}$, maior será o tempo esperado para que o choque se dissipe pela metade, isto é, maior será a medida de meia-vida estimada. Por exemplo, se $\alpha_{1}=\frac{1}{2}$, então, será preciso de um período para que metade do choque seja eliminada.

Ainda com relação à medida anterior, se o processo for um $\operatorname{AR}(p), \operatorname{com} p>1$, a análise desta medida poderá ser realizada por meio da função de impulso e resposta (CAPORALE et al., 2004).

Para a análise em painel, serão desenvolvidos testes de raiz unitária considerando-se quatro conjuntos de dados em painéis balanceados, cada um apresentando um país-membro como referência. 
A variável em análise é dada pelo vetor:

$$
z, t=\left(\begin{array}{c}
\operatorname{rid}_{d, t}-\operatorname{rid}_{z, t} \\
\operatorname{rid}_{d, t+1}-\operatorname{rid}_{z, t+1} \\
\ldots \\
\operatorname{rid}_{d, t+n}+\operatorname{rid}_{z, t+n} \\
\operatorname{rid}_{f, t}+\operatorname{rid}_{z, t} \\
\operatorname{rid}_{f, t+1}+\operatorname{rid}_{z, t+1} \\
\ldots \\
\operatorname{rid}_{f, t+n}+\operatorname{rid}_{z, t+n} \\
\operatorname{rid}_{g, t}+\operatorname{rid}_{z, t} \\
\operatorname{rid}_{g, t+1}+\operatorname{rid}_{z, t+1} \\
\ldots \\
\operatorname{rid}_{g, t+n}+\operatorname{rid}_{z, t+n},
\end{array}\right)
$$

Em que $n$ é o número de períodos disponíveis para a análise, zé o país de referência; e $d, f$ e $g$ são os demais países-membros do Mercosul.

Se constatado que rid $z, t$ é estacionário, conclui-se que os países $d, f$, $g$ são conjuntamente integrados comercial e financeiramente ao país de referência $z$. Caso o resultado se repita em todos os quatro conjuntos de dados em painel analisados, tem-se que os quatro países-membros do Mercosul são integrados conjuntamente.

\begin{tabular}{|c|c|}
\hline VETORES & PAÍS DE REFERÊNCIA \\
\hline$r i d_{a, t}$ & Argentina \\
\hline$r i d_{b, t}$ & Brasil \\
\hline$r i d_{p, t}$ & Paraguai \\
\hline$r i d_{u, t}$ & Uruguai \\
\hline
\end{tabular}

\section{QUADRO 02 \\ VETORES DE RIDS}

O desenvolvimento dos testes de raiz unitária com dados em painel será realizado em duas etapas usando os vetores explicitados no Quadro 02. Na primeira, será desenvolvido o teste de Pesaran (teste CD, 2004) a fim de verificar a existência (ou não) de correlação entre os rids. Essa etapa é relativamente importante já que os dados macroeconômicos utilizados nesse trabalho provavelmente apresentam correlação multivariada temporal. Trata-se de um teste amplo, sendo aplicado em uma grande variedade de dados em painel, inclusive em painéis dinâmicos heterogêneos com $\mathrm{T}$ pequeno e $\mathrm{N}$ grande. Além disso, é um teste robusto quando na presença de mudanças estruturais únicas ou múltiplas. Sua hipótese nula é de que há independência entre os rids no corte transversal.

Na segunda etapa, são desenvolvidos os testes de raiz unitária de acordo com o resultado apontado pelo teste de Pesaran. Caso não ocorra correlação entre os rids, serão considerados os testes da primeira geração IPS (IM, PESARAN; SHIN, 2003) e Hadri (2000). Caso ocorra, o teste a ser considerado será o Pesaran (teste CADF, 2007). 
O teste IPS, parte da equação básica para verificar a raiz unitária em painel:

$$
\Delta \operatorname{rid}_{z, t}=\emptyset \operatorname{rid}_{z, t-1}+\sum_{j=2}^{p_{z}} \tau_{z} \Delta \operatorname{rid}_{z, t-j}+\psi_{m, z} d_{m, t}+\varepsilon_{z, t}
$$

Onde rid ${ }_{z, t}$ representa o vetor das séries de rids, $\mathrm{d}_{\mathrm{m}, \mathrm{t}}$ contém variáveis determinísticas (constante, tendência), $\Psi_{\mathrm{m}, \mathrm{z}}$ corresponde ao vetor de coeficientes do modelo, e $\mathrm{p}_{\mathrm{z}}$ é a ordem de defasagens necessárias para limpar os resíduos da regressão. Essa equação é a versão em painel do teste ADF. O teste IPS irá assumir como hipótese nula que $\phi_{\mathrm{i}}=0$ para todo i, isto é, de que cada série no painel possui raiz unitária. A hipótese alternativa é de que existe ao menos um i para o qual $\phi_{\mathrm{i}}<0$, isto é, existe ao menos um país para o qual rid ${ }_{z, t}$ é estacionário. Essa versão do teste é menos restrita do que, por exemplo, o teste Levin, Lin \& Chu (2002), que assume como hipótese alternativa que $\phi_{\mathrm{i}}<0$ para todo i, isto é, ou todos os rid ${ }_{z, t}$ possuem uma raiz unitária ou são todos estacionários.

Já o segundo teste (HADRI, 2000) é, por sua vez, a contrapartida para dados em painel do teste KPSS. Ele é baseado no teste do Multiplicador de Lagrange sobre os resíduos e fornece três tipos de resultados de acordo com o pressuposto assumido para a distribuição dos resíduos: I. homoscedásticos (variância constante e idênticas entre os rids); II. heteroscedásticos; ou III. permite o controle para dependência serial (SerDep). Sua hipótese nula é de que todas as séries são estacionárias, contra a hipótese alternativa de que há uma raiz unitária para todos os países.

Passando para a exposição do segundo teste, também conhecido por CADF (Crossectionally Augmented Dickey-Fuller), tem-se que o seu objetivo é tentar capturar a dependência no corte transversal pela inclusão de dois novos termos:

$$
\Delta r i d_{z, t}=a_{z}+\rho_{z}^{*} \operatorname{rid}_{z, t-1}+d_{0} r i d_{t-1}+d_{1} \Delta \overline{r l d}_{\mathrm{t}}+\varepsilon_{t}
$$

Aqui, $\overline{r l d}_{\mathrm{t}-1}$ representa a média (dentre os diferenciais da taxa de juros real) de rid $_{z, t-} 1$. Pode-se aumentar essa regressão incluindo defasagens de $\Delta \overline{r l d}_{\mathrm{t}-\mathrm{k}}$ de modo a limpar por completo a dependência no corte transversal. A equação final a ser estimada será:

$$
\Delta r i d_{z, t}=a_{i}+\rho_{z}^{*} r i d_{z, t-1}+d_{0} \overline{r l d}_{\mathrm{t}-1}+\sum_{j=0}^{p} d_{j+1} \Delta \overline{r l d}_{\mathrm{t}-\mathrm{j}}+\sum_{k=1}^{p} c_{k} \Delta r i d_{z, t-k}+\varepsilon_{z, t}
$$

A vantagem desse teste é, essencialmente, a de não precisar estimar os fatores comuns. Obtém-se o resultado do teste como uma média simples das estatísticas t de $p_{z}$, que possui distribuição não padrão.

\section{DADOS}

Os dados utilizados para o cálculo dos são do Fundo Monetário Internacional (FMI). As fontes primárias correspondem à taxa de juros de depósito (\% a.a.) e a taxa de inflação ao produtor (\% a.a.), utilizados numa frequência mensal.

É necessário fazer duas considerações principais sobre a amostra utilizada, uma vez que os testes têm relação direta com a qualidade dos dados na fonte. Em primeiro lugar, cabe ressaltar que a Argentina apresentou problemas de credibilidade em suas informações de inflação prestadas ao $\mathrm{FMI}^{(5)}$. Por essa razão, os resultados apresentados, que

(5) Ver, por exemplo, a discussão e a evidência que são apresentadas em Cavallo (2013). 
envolvem esse país, particularmente, precisarão ser lidos com cautela. No entanto, vale a pena ressaltar, se o erro de construção dessa variável não afetar a dinâmica da variável, os tratamentos econométricos realizados para a maioria dos testes (por exemplo, ao se trabalhar com a primeira diferença) serão capazes de eliminar ou amenizar tais problemas. Em segundo lugar, é preciso mencionar que seria possível trabalhar com taxas dos títulos de tesouro para os juros e com preços ao consumidor para alguns países. É também provável que essas variáveis, principalmente juros, tivessem uma maior aderência aos pressupostos teóricos. No entanto, optou-se por utilizar inflação ao produtor e juros de depósito para o objetivo de uniformização e comparabilidade dos cálculos, uma vez que essas variáveis estavam disponíveis para todos os países do Mercosul na base de dados do FMI. Ademais, as taxas de depósito parecem amenizar problemas com vencimentos diferentes, visto que as taxas de tesouro reportadas ao FMI correspondem às médias de títulos com vencimentos divergentes. Por se tratar de países que apresentam alta volatilidade macroeconômica no início da década de 90 e, baseando-se no fato de que o Brasil é o país com maior representatividade econômica do bloco ${ }^{(6)}$, optou-se pelo início da análise em julho de 1995, período em que os juros e a inflação brasileira já haviam convergido para patamares razoáveis.

\section{RESULTADOS}

O Quadro 03 resume as estatísticas dos testes ADF e DF-GLS para os rids bilaterais para jul./1995 a set./2011. Como pode ser visto, o teste ADF rejeita a hipótese nula de raiz unitária nos rids, enquanto o teste DF-GLS não consegue rejeitar a hipótese nula para três dos diferenciais. Conforme citado, o teste DF-GLS apresenta maior poder do que o ADF por, dentre outros pontos, tratar de maneira mais robusta o problema de heteroscedasticidade, portanto, a hipótese de integração entre Argentina e Uruguai, Brasil e Paraguai e Paraguai e Uruguai não é corroborada por esses resultados iniciais.

\begin{tabular}{|c|c|c|c|c|}
\hline VARIÁVEL & $\begin{array}{c}\text { COMP. } \\
\text { DETERMINISTA }\end{array}$ & DEFASAGENS & ADF & DF-GLS \\
\hline$r i d_{a b, t}$ & Constante & 4 & $-4.100^{* * *}$ & $-1.731^{*}$ \\
\hline$r i d_{a p, t}$ & - & 2 & $-6.490^{* * *}$ & $-6.496^{* * *}$ \\
\hline$r i d_{a u, t}$ & - & 4 & $-2.632^{* * *}$ & -1.477 \\
\hline$r i d_{b p, t}$ & Constante & 1 & $-4.142^{* * *}$ & -1.065 \\
\hline$r i d_{b u, t}$ & - & 3 & $-3.328^{* * *}$ & $-2.979^{* * *}$ \\
\hline$r i d_{p u, t}$ & - & 4 & $-3.384^{* * *}$ & -1.299 \\
\hline
\end{tabular}

QUADRO 03

ResultAdOS DO TESTE DE RAIZ UNITÁRIA ADF E DF-GLS - JUL./1995 - SET./2011

***Estatisticamente significante a $1 \%$;

**Estatisticamente significante a $5 \%$;

*Estatisticamente significante a $10 \%$.

(6) Segundo os dados do Fundo Monetário Internacional de 2011, a participação do Brasil no PIB do Mercosul é de 75\%. 
No entanto, uma análise gráfica das séries em questão permite notar a possível presença de quebras estruturais. Como se sabe, uma possível mudança estrutural nas séries pode levar à sobreaceitação da hipótese nula de não estacionariedade quando, em verdade, a série é estacionária.

Os resultados do teste de Zivot \& Andrews (1992) podem ser vistos no Quadro 04: rejeita-se a não estacionariedade para todas as séries, isto é, há evidência de integração bilateral entre os países.

\begin{tabular}{|c|c|c|c|}
\hline VARIÁVEL & DEFASAGENS & PONTO CRÍTICO & ESTATÍSTICA DO TESTE \\
\hline$r i d_{a b, t}$ & 2 & Abr./2003 & $-6.437^{* * *}$ \\
\hline$r i d_{a p, t}$ & 2 & Fev./2002 & $-7.052^{* * *}$ \\
\hline$r i d_{a u, t}$ & 2 & Jan./2001 & $-7.383^{* * *}$ \\
\hline$r i d_{b p, t}$ & - & Mar./2004 & $-5.173^{* * *}$ \\
\hline$r i d_{b u, t}$ & 3 & Mai./2003 & $-4.698^{* *}$ \\
\hline$r i d_{p u, t}$ & 3 & Jan./2002 & $-4.806^{* *}$ \\
\hline
\end{tabular}

\section{QUADRO 04}

TESTE DE RAIZ UNITÁRIA - ZIVOT \& ANDREWS - JUL./1995 - SET./2011

\footnotetext{
***Estatisticamente significante a $1 \%$;

**Estatisticamente significante a 5\%;

*Estatisticamente significante a $10 \%$.
}

Tendo em vista que os resultados acima, de forma geral, apontam para a estacionariedade dos rids, parte-se para a análise dos coeficientes autorregressivos via janela móvel e via estimação recursiva, assumindo-os como processos AR(1). O Quadro 05 apresenta a média dos coeficientes autorregressivos estimados. Todos os parâmetros estão abaixo do valor unitário, porém, são bastante persistentes (com exceção do rid de Brasil e Paraguai). O Gráfico 05 (Anexos) apresenta os resultados dos coeficientes autorregressivos estimados por janela móvel de 48 meses.

Os coeficientes estimados recursivamente para a série do período 1995-2011 corroboram a volatilidade inicial da série. Como já apontado, o peso de cada dado adicional neste método possui valor decrescente, o que poderia explicar o comportamento suave dos coeficientes após os pontos de quebras estimados pelo teste de Zivot e Andrews (1992) anteriormente descritos. Quando calculados, via método de janelas móveis, nota-se que os coeficientes estimados são ligeiramente inferiores aos encontrados pelo método anterior. Nota-se particularmente, no Gráfico 04 (Anexos), que o Brasil e Paraguai demonstram uma dinâmica crescente integração, muito maior do que os outros parceiros (isto é, o valor do coeficiente autorregressivo diminui consideravelmente).

\begin{tabular}{|c|c|c|}
\hline VARIÁVEL & MÉTODO RECURSIVO & JANELA MÓVEL \\
\hline$r i d_{a b, t}$ & 0.894 & 0.783 \\
\hline$r i d_{a p, t}$ & 0.806 & 0.672 \\
\hline
\end{tabular}


Continuação

\begin{tabular}{|c|c|c|}
\hline VARIÁVEL & MÉTODO RECURSIVO & JANELA MÓVEL \\
\hline$r i d_{a u, t}$ & 0.939 & 0.911 \\
\hline$r i d_{b p, t}$ & 0.839 & 0.364 \\
\hline$r i d_{b u, t}$ & 0.953 & 0.935 \\
\hline$r i d_{p u, t}$ & 0.910 & 0.798 \\
\hline
\end{tabular}

\section{QUADRO 05}

\section{COEFICIENTES AUTORREGRESSIVOS ESTIMADOS EM T = SET./2011}

Com relação à análise da meia-vida no Quadro 06, pode-se observar que o menor valor encontrado é o de 3.2 meses, para a série rid ${ }_{\text {ap.t }}$, enquanto o maior valor é de 14.5 meses, para. Esses valores são baixos se comparados com a meia-vida estimada para a PPC - Rogoff (2006), por exemplo, pois apresenta várias evidências que colocam a meia-vida da PPC entre 3 a 5 anos - e um pouco mais altos dos encontrados por Ferreira e León-Ledesma (2007) para os diferenciais de juros entre uma amostra de economias emergentes (entre elas, o Brasil e a Argentina) e os EUA: 5,5 meses quando a raiz é estimada pelo ADF.

\begin{tabular}{|c|c|}
\hline VARIÁVEL & MEIA-VIDA (EM MESES) \\
\hline rid $_{a b, t}$ & 6.2 \\
\hline rid $_{a p, t}$ & 3.2 \\
\hline rid $_{a u, t}$ & 11.0 \\
\hline$r i d_{b p, t}$ & 4.0 \\
\hline rid $_{b u, t}$ & 14.5 \\
\hline$r i d_{p u, t}$ & 7.4 \\
\hline
\end{tabular}

QUADRO 06

\section{MEIA-VIDA ESTIMADA - RIDS}

Passando-se aos resultados dos testes de raiz unitária em dados em painel, iniciou-se a análise pelo teste CD no Quadro 07. Este conclui que todos os rids em análise apresentam correlação entre os diferenciais de juros. Dessa forma, os resultados dos testes IPSe de Hadri não são válidos para estas séries e, assim, será considerado apenas o resultado do teste CADF no Quadro 08.

\begin{tabular}{|c|c|c|}
\hline VARIÁVEL & ESTATíSTICA DO TESTE & P-VALOR \\
\hline$r i d_{a, t}$ & 13.31 & 0.0000 \\
\hline$r i d_{b, t}$ & 15.36 & 0.0000 \\
\hline$r i d_{p, t}$ & 3.30 & 0.0001 \\
\hline$r i d_{u, t}$ & 14.47 & 0.0000 \\
\hline
\end{tabular}

QUADRO 07

TESTE CD - JUL./1995 - SET./2011 


\begin{tabular}{|c|c|c|}
\hline \multicolumn{2}{|c|}{ Continuacão } \\
\hline VARIÁVEL & ESTATíSTICA DO TESTE & P-VALOR \\
\hline$r i d_{a, t}$ & -2.742 & 0.0033 \\
\hline$r i d_{b, t}$ & -4.732 & 0.0000 \\
\hline$r i d_{p, t}$ & -4.056 & 0.0001 \\
\hline$r i d_{u, t}$ & -5.069 & 0.0000 \\
\hline
\end{tabular}

$$
\begin{gathered}
\text { Quadro } 08 \\
\text { Teste CADF - JUL./1995 - SET./2011 }
\end{gathered}
$$

Os resultados encontrados pelo teste CADF apontaram para a estacionariedade do diferencial da taxa de juros reais para todas as séries em um nível de 5\% de significância. Assim, de uma forma geral, os testes de raiz unitária em painel chegaram a evidenciar de que há integração financeira e comercial entre os países-membros do Mercosul.

\section{CONSIDERAÇÕES FINAIS}

Este estudo teve como objetivo analisar o grau de integração conjunta, financeira e comercial, entre os países-membros do Mercosul.

É bem documentado na literatura que houve evolução relevante no comércio de bens intrabloco dentro do período analisado, desde a assinatura do Tratado de Assunção em 1991. Esse apresentou crescimento médio anual superior à taxa de crescimento do comércio extrabloco, a despeito de alguns períodos de instabilidade no cenário macroeconômico desses países, sendo as mais importantes a crise da desvalorização da moeda brasileira em 1999 e a crise da dívida argentina em 2001. Em contraposição ao mercado de bens, que evoluiu favoravelmente, não há evidência descritiva de que o mercado de ativos apresentou desenvolvimento mais rápido entre as economias do bloco.

Dada essa caracterização, foram realizados testes para uma investigação mais formal sobre a integração conjunta dos mercados de bens e ativos das economias do Mercosul. Iniciou-se a análise com testes de estacionariedade das séries dos diferenciais de juros reais, investigando-as tanto individualmente quanto agrupadas em painel. Posteriormente, considerou-se a presença de quebras estruturais.

Os resultados com o teste ADF apontam para a estacionariedade das séries, enquanto existem divergências para alguns pares de diferenciais ao se utilizar o DF-GLS. Quando se considera a possibilidade de uma quebra estrutural, estimada pelo teste de Zivot \& Andrews (1992), as séries apresentam evidências de estacionariedade. Por fim, os testes em painel (CADF) corroboraram a visão de que os países em questão são integrados de julho de 1995 a setembro 2011. Embora existam algumas divergências entre os resultados estatísticos, o que não é incomum quando se trata de testes de raiz unitária, o conjunto da evidência probabilística revelada nesse artigo sugere que as séries em questão são estacionárias.

A partir da conclusão acima, foi possível realizar a análise da persistência dos diferenciais de juros reais, mediante a análise da medida de meia-vida (associada aos coefi- 
cientes autorregressivos). As medidas de meia-vida variaram de 4.6 a 14.5 meses, valores um pouco superiores à média encontrada em trabalhos anteriores.

Também foi analisada a evolução dos coeficientes autorregressivos, considerando que os diferenciais podem ser aproximados por um processo $\mathrm{AR}(1)$, utilizando estimação recursiva e via janela móvel. As medidas de persistência, em sua maioria, diminuíram ao longo dos últimos anos, evidenciando que a integração entre os países está aumentando, ainda que de forma lenta.

\section{BIBLIOGRAFIA}

AZEVEDO, André Filipe Zago de; MASSUQUETTI, Angélica. TEC no âmbito do Mercosul: teoria e prática. Análise Econômica, Porto Alegre, v. 27, pp. 07-23, 2009.

BAUMANN, Renato. Mercosul: Origens, ganhos, desencontros e perspectivas. In: BAUMANN, Renato (org.). Mercosul - Avanços e desafios da integração. Brasília: IPEA/CEPAL, 2001.

CAPORALE, Guglielmo Maria; CERRATO, Guglielmo Maria, SPAGNOLO, Nicola. Measuring half-lives: using a nonparametric bootstrap approach. Applied Financial Economics Letters, v. 01, n. 01, pp. 01-04, 2005.

CAVALLO, Alberto. Online and official price indexes: Measuring Argentina's inflation. Journal of Monetary Economics, v. 60, n. 2, pp. 152-165, 2013.

CHAKRABORTY, Avik.; EVANS, George. Can perpetual learning explain the forward premium puzzle? Journal of Monetary Economics, v. 55, n. 03, pp. 477-490, 2008.

DIAS, Daniel; MARQUES, Carlos Robalo. Using Mean reversion as a measure of persistence. European Central Bank, Working Paper, n. 450, 2005.

FELDSTEIN, Martin; HORIOKA, Charles. Domestic savings and international capital ows. Economic Journal, v. 90, n. 358, pp. 314-329, 1980.

FERREIRA, Alex Luiz. The real Interest rate parity hypothesis: an investigation for developed and emerging markets. 2005. 269 p. Tese (Doutorado em Economia) - Departamento de Economia, Universidade de Kent.

FERREIRA, Alex Luiz. The Simultaneity Bias of the Uncovered Interest Rate Parity: Evidence for Brazil. Universidade de São Paulo, Faculdade de Economia, Administração e Contabilidade de Ribeirão Preto, Working Papers, n. 08/20, Janeiro, 2009.

FERREIRA, Alex Luiz. LEON-LEDESMA, Miguel. Does the real interest parity hypothesishold? Evidence for developed and emerging markets. Journal of International Money and Finance, v. 26, n. 03, pp. 364-382, 2007.

FERREIRA, Alex Luiz; SILVA, Roseli da. Real interest parity decomposition. Estudos Econômicos, São Paulo, v. 39, n. 03, pp. 489-512, 2009.

HADRI, Kaddour. Testing for stationarity in heterogeneous panel data. Econometrics Journal, Royal Economic Society, v. 03, n. 02, pp. 148-161, 2000.

IM, Kyung So. PESARAN, Mohammad Hashem; SHIN, Yongcheol. Testing for Unit Roots in Heterogeneous Panels. Journal of Econometrics, v. 115, pp. 53-74, 2003.

LEVIN, Andrew; LIN, Chien-Fu; CHU, Chia-Shang James. Unit root in panel data: Asymptotic and Ânite-sample Properties. Journal of Econometrics, v. 108, n. 01, pp. 01-24, 2002.

MCCALLUM, John. National Borders Matter: Canada-U. S. Regional Trade Patterns. The American Economic Review, v. 85, n. 03, pp. 615-623, 1995. 


\section{APÊNDICES}
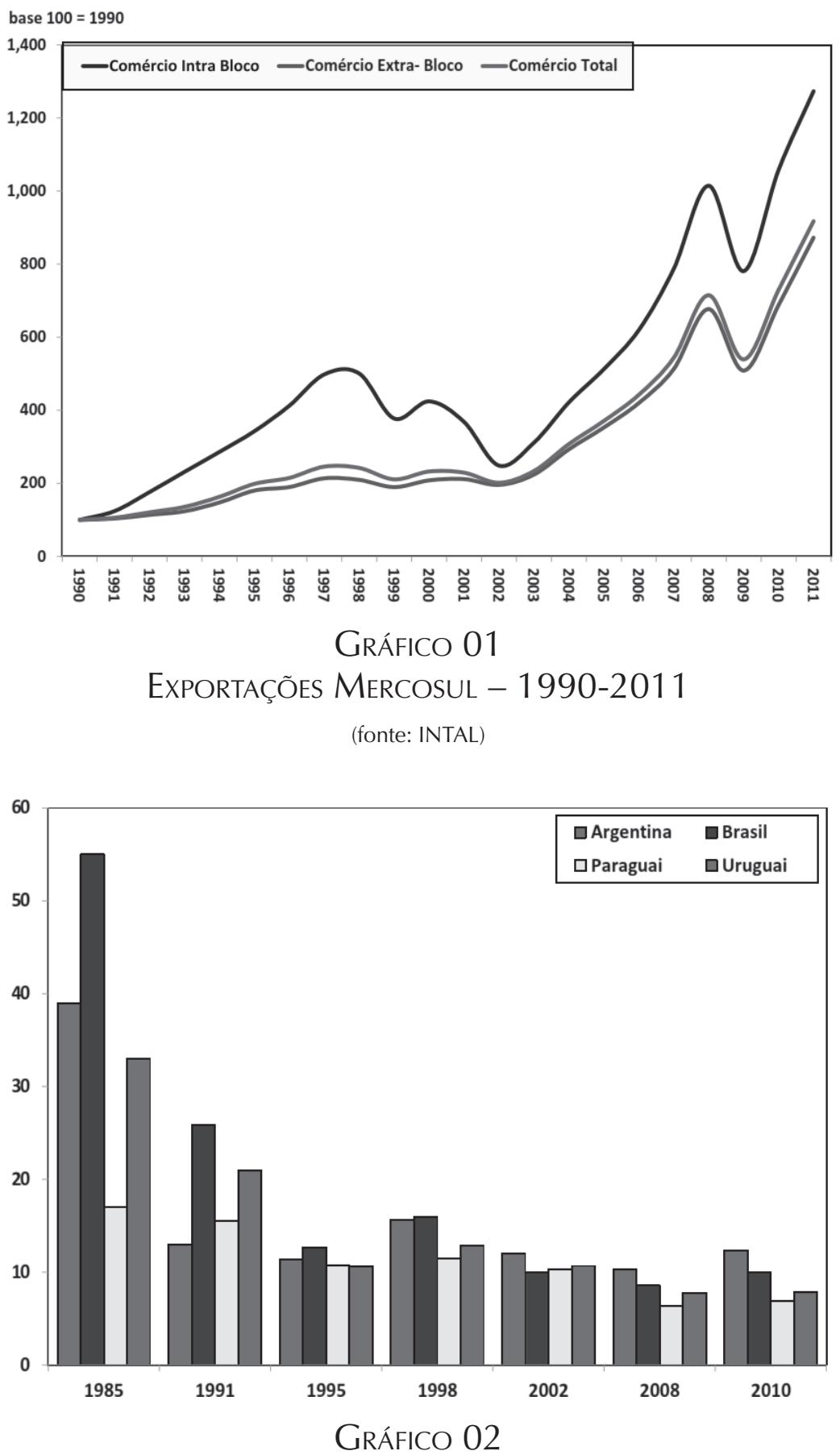

EVolução da tarifa média dos Países do Mercosul

(Fonte: Comtrade-Unctad) 


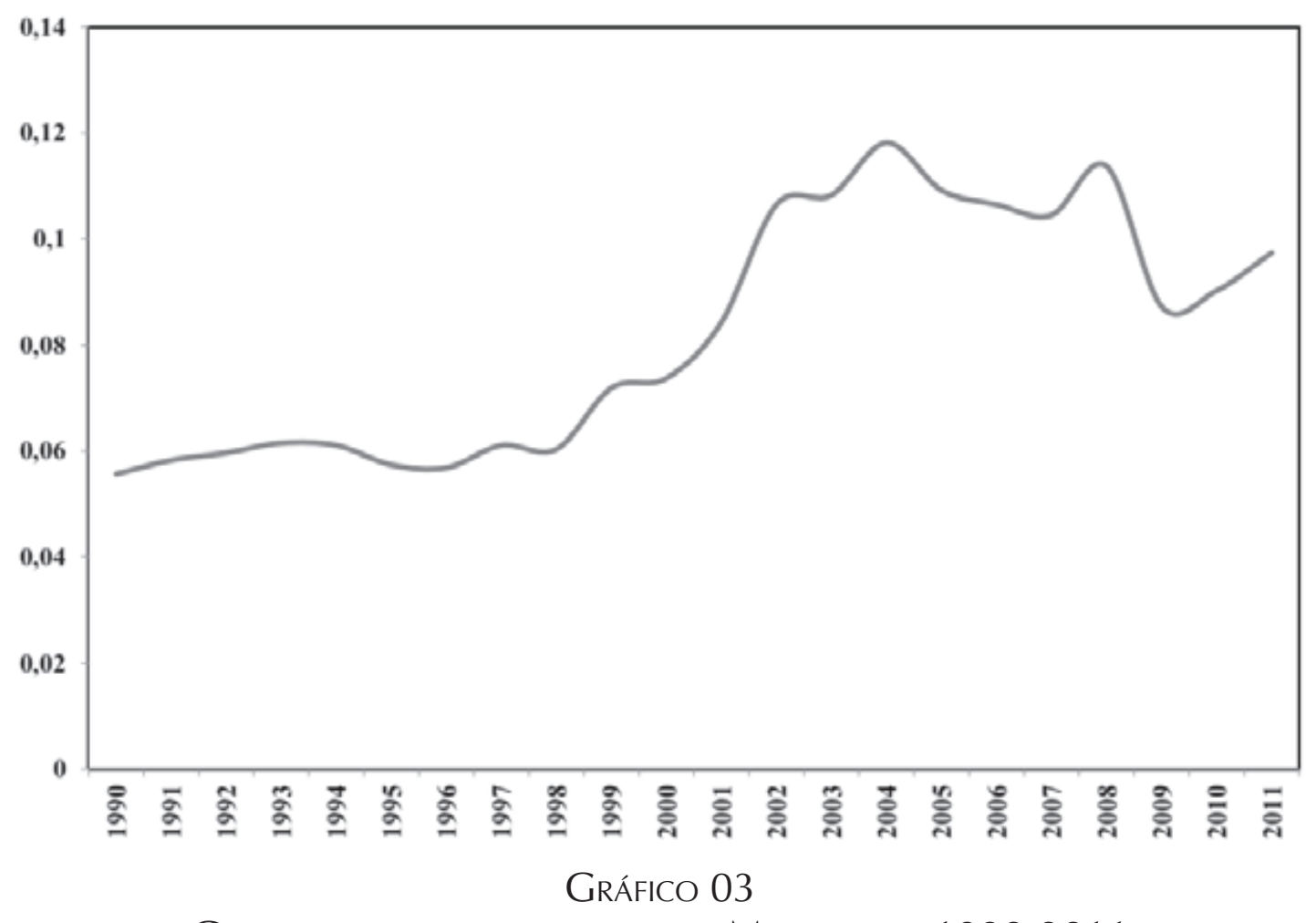

Grau de abertura comercial do Mercosul - 1990-2011

(Fonte: FMI) 
(a) rid $_{a b, t}$

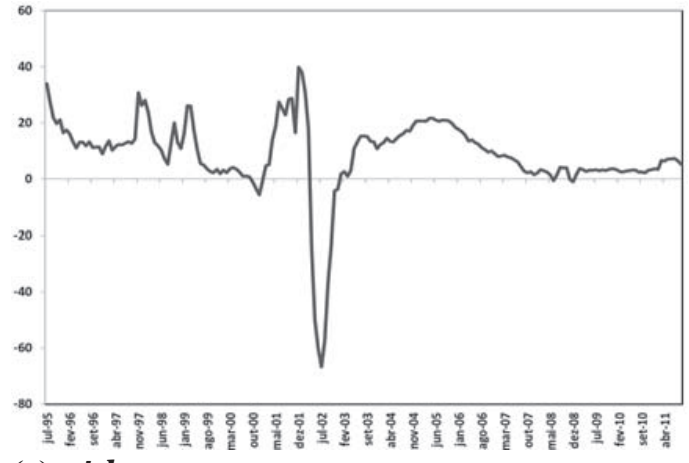

(c) rid $_{\text {au,t }}$

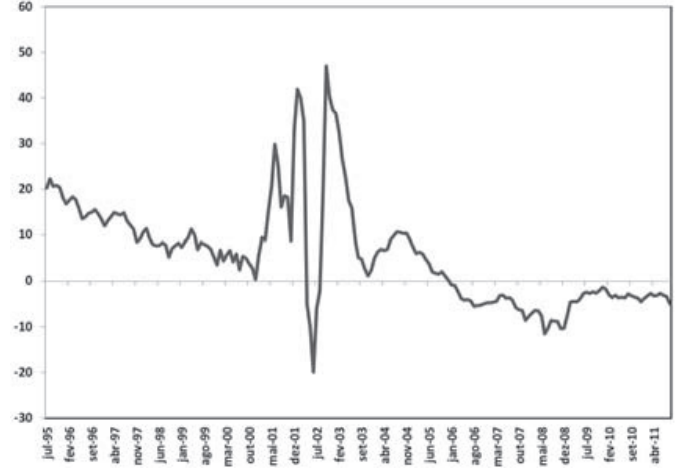

(e) rid $_{b u, t}$

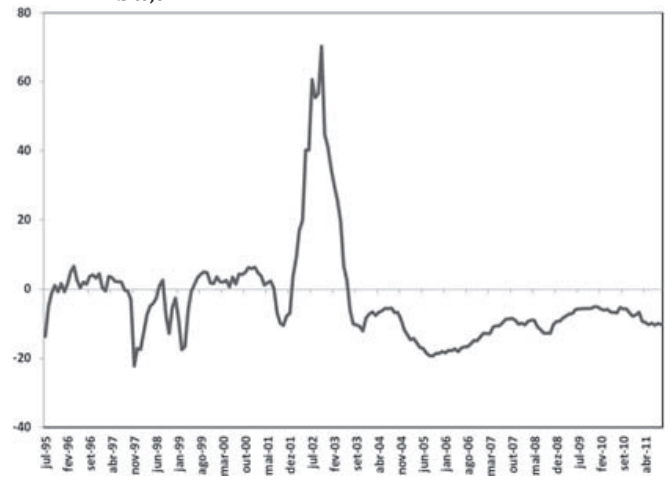

(b) rid $_{\text {ap,t }}$

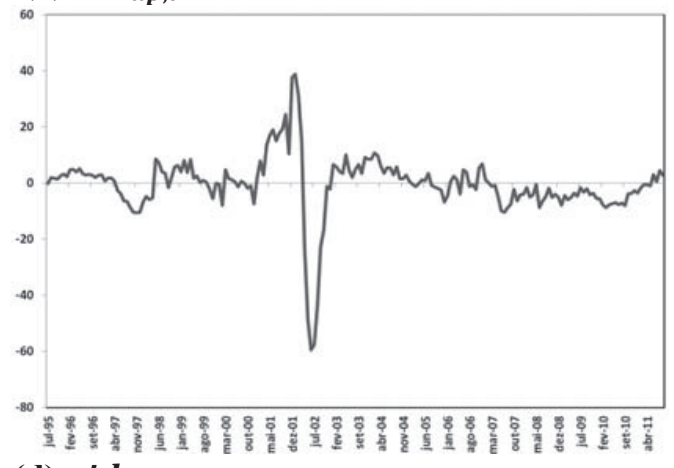

(d) rid $_{b p, t}$

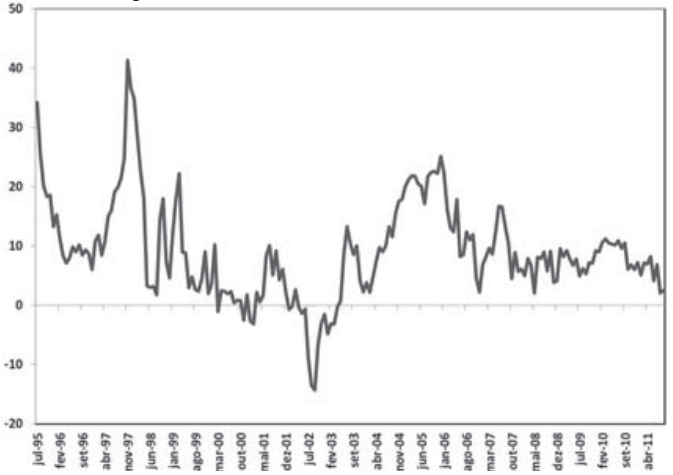

(f) rid $_{\text {pu,t }}$

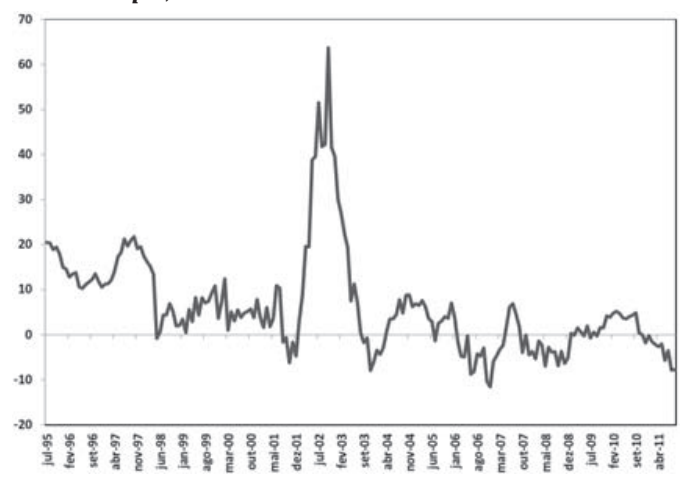

GRÁFICO 04

EVOLUÇÃO TEMPORAL DOS RIDS - JUL./1995 - SET./2011 

(a) $\boldsymbol{r i d} a b, t$
(b) $\operatorname{rid}$ ap,t
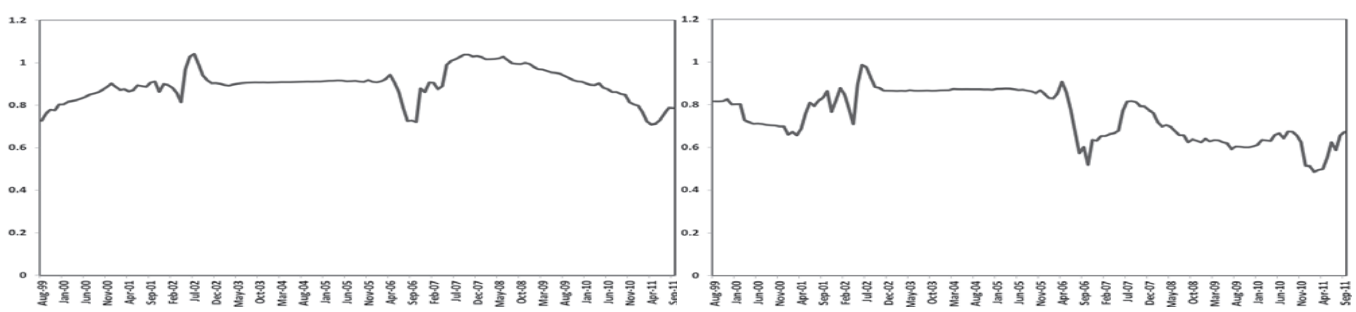

(c) $\operatorname{rid}_{a u, t}$

(d) $\boldsymbol{r i d}$ bp,t
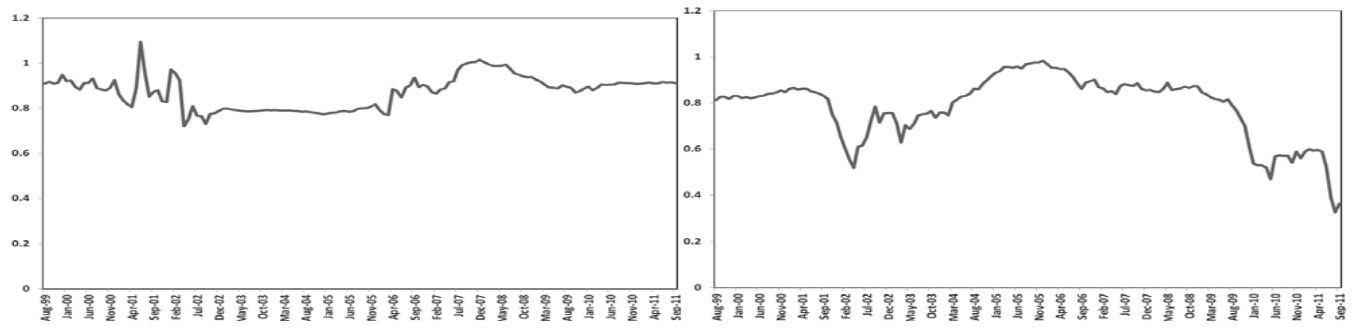

(e) $\boldsymbol{r i d}$ bu,t

(f) $\boldsymbol{r i d}_{p u, t}$

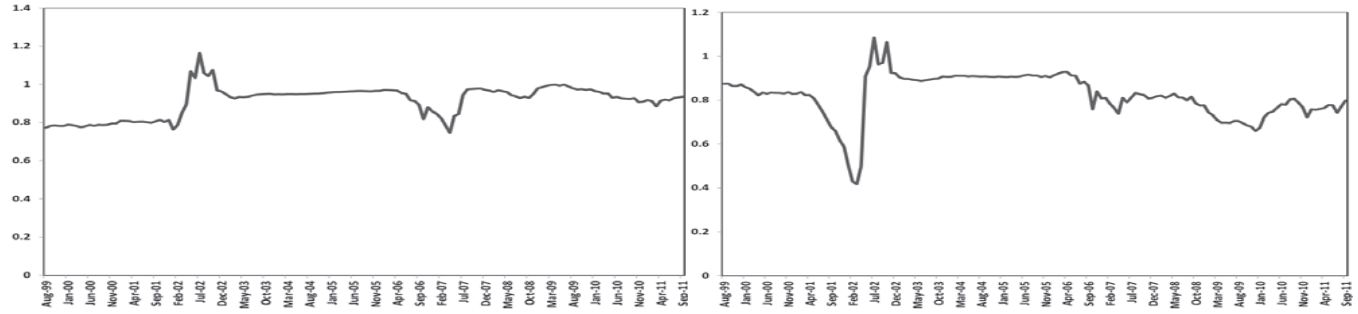
(e) rid $_{b u, t}$
(f) rid $_{p u, t}$

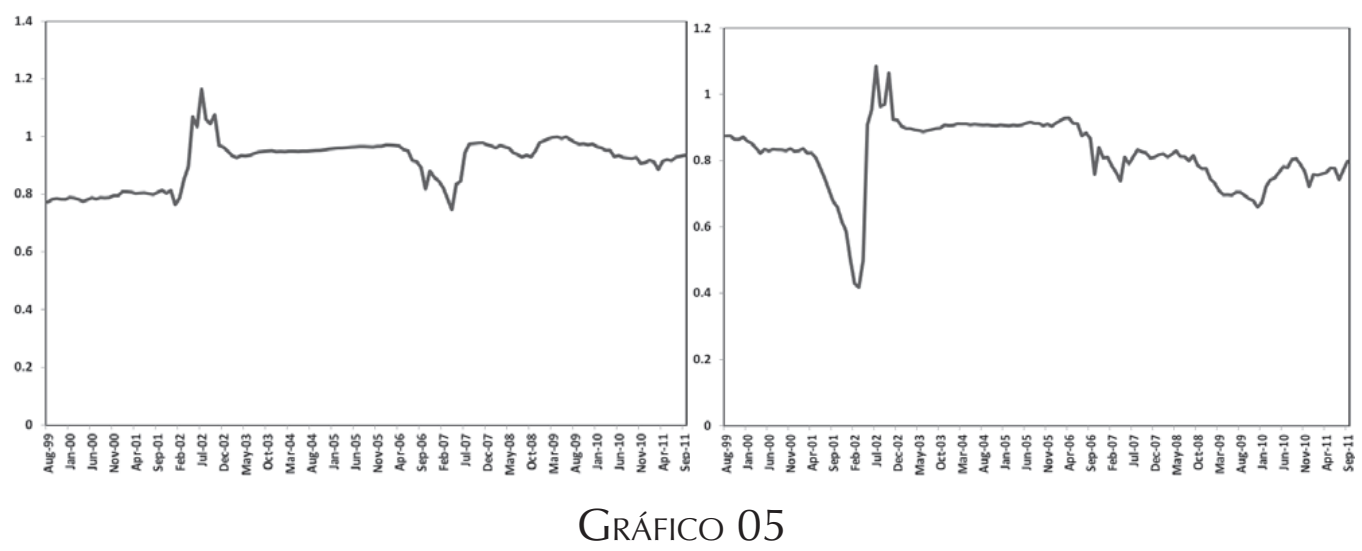

ESTIMAÇÃO POR JANELA MÓVEL (48 MESES) DOS COEFICIENTES AUTORREGRESSIVOS DOS RIDS 